\title{
Extracutaneous mastocytoma of colon: a case report and literature review
}

\author{
Min Su Chu', Eui Joong Kim² \\ ${ }^{1}$ Department of Internal Medicine, Jeonju Korea Hospital, Jeonju; ${ }^{2}$ Department of Internal Medicine, Wonkwang University College of Medicine, Iksan, Korea
}

Extracutaneous mastocytoma is a rare benign tumor composed of mature mast cells and is located in tissues other than the skin. We report the case of a 61-year-old male who was diagnosed with extracutaneous mastocytoma via colonoscopic polypectomy and biopsy. To our knowledge, this was the first case of a solitary extracutaneous mastocytoma of the colon. We reported this case and reviewed the literature.

Keywords: Colon; Extracutaneous mastocytoma; Mast cell; Polypectomy

\section{INTRODUCTION}

The World Health Organization (WHO) classification ${ }^{1}$ defines mastocytosis as a condition characterized by differentiated mast cells in one or more organs. It is classified into several types, according to its characteristics. Among these, extracutaneous mastocytoma is a rare subtype. It can invade any tissue and presents as a solitary benign tumor located in organs aside from the skin. There have been no reports on systemic mastocytosis. The authors examined the case of an extracutaneous mastocytoma in the colon in a male who visited for a medical checkup. A literature review was also conducted since this was the first reported case worldwide.

\footnotetext{
Received: November 19, 2020 Revised: March 17, 2021

Accepted: April 13, 2021

Correspondence: Eui Joong Kim

Department of Internal Medicine, Wonkwang University Hospital, 895

Muwan-ro, Iksan 54538, Korea

E-mail: blueliebe98@naver.com
}

(a) This is an Open Access article distributed under the terms of the Creative Commons Attribution Non-Commercial License (http://creativecommons.org/licenses/by-nc/4.0/) which permits unrestricted non-commercial use, distribution, and reproduction in any medium, provided the original work is properly cited.

\section{CASE REPORT}

A 61-year-old man visited the hospital for a medical checkup. Colonoscopy revealed a $1-\mathrm{cm}$ mass with a white gyral pattern and a slightly swollen transverse colon. He was later moved to the Wonkwang Digestive Diseases Center for mucosal resection after injection of epinephrine and saline mixed fluid (Fig. 1). The biopsy findings showed mature and normally differentiated mast cells only (Figs. 2, 3). He did not complain of digestive symptoms or other specific symptoms. Blood tests, further history taking, physical examination, plain radiography of the chest and abdomen, peripheral blood smear, and serum tryptase were conducted to confirm whether it was a single disease entity or associated with a systemic disease during the classification of mastocytosis. There were no unusual physical examination findings, such as skin lesions, hepatomegaly, and splenomegaly. The blood tests, peripheral blood smear, and imaging tests were unremarkable. The serum tryptase levels were within the normal range at $5.3 \mu \mathrm{g} / \mathrm{L}$. The patient's medical history included hypertension and diabetes, and was otherwise unremarkable. In conclusion, the patient had no other findings other than the lesion, consisting of mature mast cells in the transverse colon. Therefore, the patient did not undergo further bone marrow biopsy or molecular testing following 


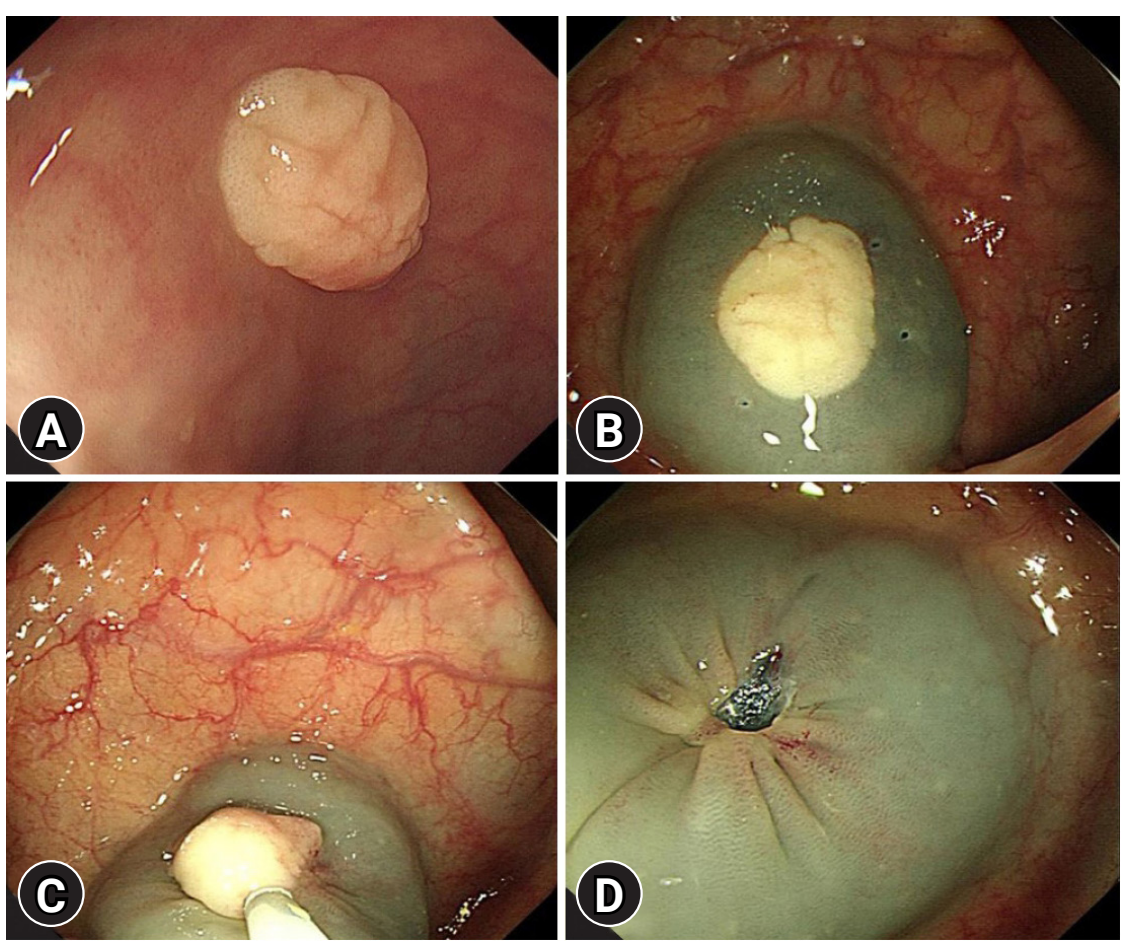

Fig. 1. Serial images of colonoscopic polypectomy. (A) Colonoscopic image showing slightly elevated whitish gyral pattern mass. (B, C) Endoscopic resection was attempted and en bloc resection was performed. (D) Complete resection was achieved without any residual tissue.
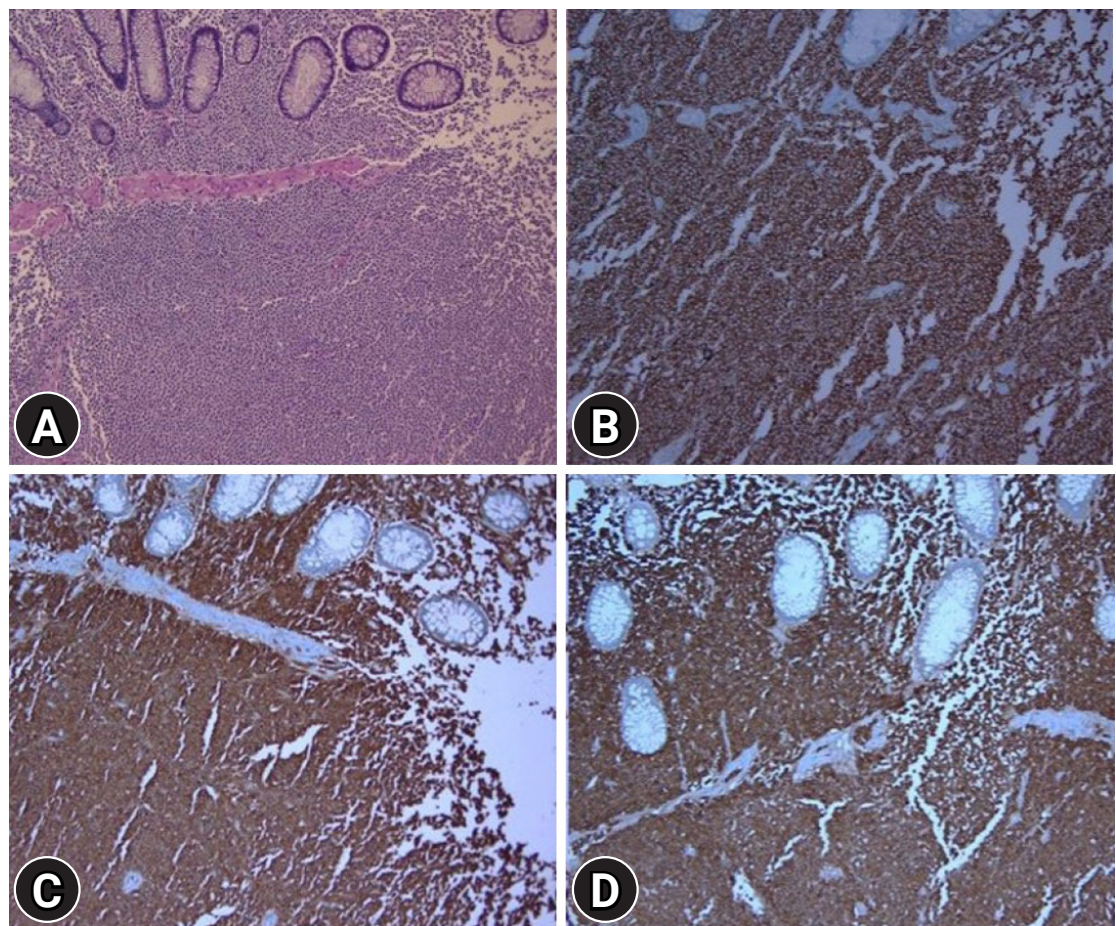

Fig. 2. Histologic features of the endoscopically resected specimen. (A) Diffuse infiltration of monotonous small round cells (hematoxylin and eosin, $\times 100$ ). (B) Positive staining for c-kit (immunohistochemistry, $\times 100$ ). (C) Positive staining for leukocyte common antigen (immunohistochemistry, $\times 100$ ). (D) Positive staining for CD68 (immunohistochemistry, $\times 100$ ). 

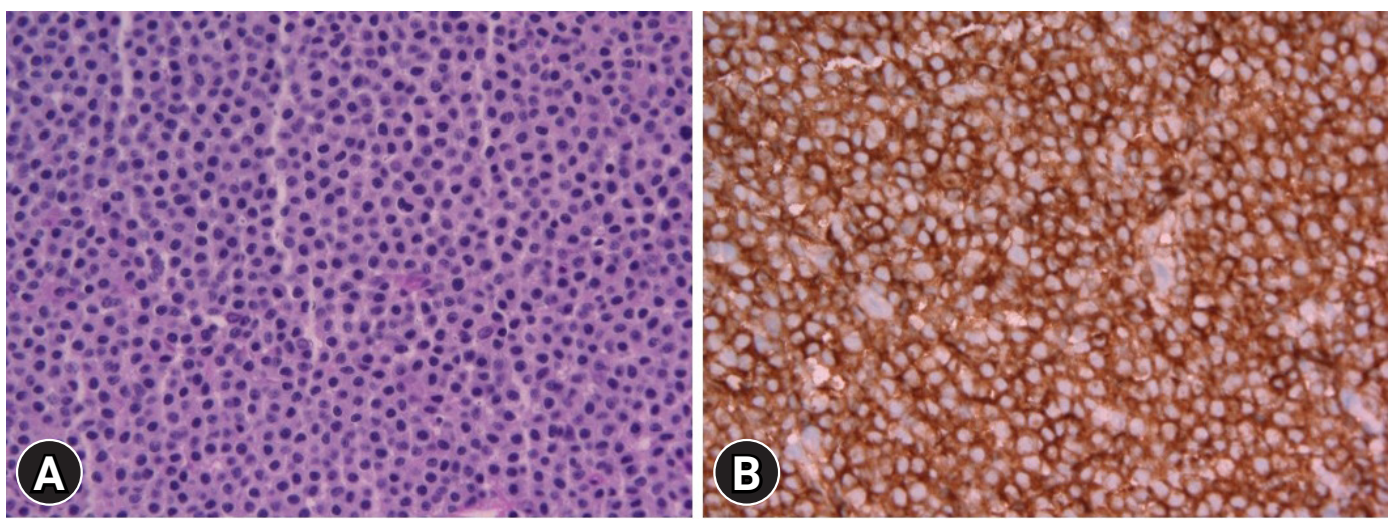

Fig. 3. Histologic images taken at high-power field. (A) Diffuse infiltration of monotonous small round cells (hematoxylin and eosin, $\times 400$ ). (B) Cytoplasmic staining with membrane accentuation for c-kit (immunohistochemistry, $\times 400$ ).

the diagnostic algorithm of the NCCN guidelines ${ }^{2}$ for systemic mastocytosis. He was diagnosed with extracutaneous mastocytoma of the colon. After that, he was recommended a follow-up colonoscopy, but he did not revisit.

\section{DISCUSSION}

The prevalence of overt mastocytosis is approximately 10 per 100,000 people. ${ }^{3}$ Among patients, $80 \%$ have skin lesions. $\mathrm{Cu}-$ taneous mastocytoma occurs in approximately $10 \%$ to $15 \%$ of cutaneous mastocytosis cases in children, and it is rare in adults, with 10 to 20 reported cases. ${ }^{4-6}$ In contrast, extracutaneous mastocytoma is rare, with only a few cases. Symptomatic therapy is the main treatment for cutaneous mastocytoma in children. In most cases, eliminating or avoiding the trigger as a preventive measure is sufficient and antihistamines may be taken to relieve symptoms. ${ }^{5}$ In adults, antihistamines or corticosteroids have been administered to relieve symptoms, but in most cases, the lesions were excised. ${ }^{6}$ The prognosis of cutaneous mastocytoma is excellent in children, and it disappears spontaneously or significantly improves before puberty. ${ }^{5}$ However, due to the few adult cases, the clinical course in this population remains unclear. In some symptomatic cases of extracutaneous mastocytoma, surgical resection of the lesions either relieved symptoms or resulted in a cure. There was no recurrence during the follow-up. In this case, the patient was asymptomatic, and the extracutaneous mastocytoma was incidentally detected during a medical examination. Only a few cases of extracutaneous mastocytoma have been reported, so treatment guidelines have not been established. Following surgical removal, regular
Table 1. Classification of mastocytosis

\begin{tabular}{ll}
\hline Disease entities & \multicolumn{1}{c}{ Subtype } \\
\hline Cutaneous mastocytosis & • Urticaria pigmentosa/maculopapulous \\
& cutaneous mastocytosis \\
& - Diffuse cutaneous mastocytosis \\
& - Mastocytoma of skin \\
& - Indolent SM \\
& - Smouldering SM \\
- SM with an associated hematologic & non-mast cell-lineage disease \\
& - Aggressive SM \\
& - Mast cell leukemia \\
& \\
\hline
\end{tabular}

Modified from Valent et al. Blood 2017;129:1420-1427.

$\mathrm{SM}$, systemic mastocytosis.

follow-up is recommended to monitor the disappearance of symptoms.

The WHO classification defines mast cell disease as a disease characterized by excessive mast cell proliferation in one or more organs. It has several types, depending on its characteristics (Table 1). ${ }^{1}$ Among these, a diagnosis of extracutaneous mastocytoma is made when there is no basis for systemic mastocytosis during mastocytosis classification, and the normally differentiated mast cells form solitary benign lesions in organs other than the skin. Microscopically, mastocytosis exhibits focal accumulation of mast cells with typical histological and cytomorphological properties. In many cases, multifocal dense and sharply demarcated infiltrates of mast cells are observed in histological lesions. ${ }^{7}$ In extracutaneous focal mast cell tumors without systemic involvement, mastocytoma can be distin- 
Table 2. Endoscopic features reported in patients with systemic mastocytosis with gastrointestinal symptoms

\begin{tabular}{llll}
\hline Esophagus & Stomach and duodenum & \multicolumn{1}{c}{ Small intestine } & Colon and rectum \\
\hline Esophagitis & Peptic ulcer & Thickened jejunal folds with edema & Nodular lesions \\
Stricture & Thickened folds & Dilated small bowel & Urticarial lesion in the rectum \\
Varices & Nodular mucosal lesions & Associated sprue-like mucosal changes & Multiple polypoid lesions \\
& Urticarial lesions & & Diffuse intestinal telangiectasis \\
\hline
\end{tabular}

Modified from Jensen. Hematol Oncol Clin North Am 2000;14:579-623. ${ }^{8}$

Table 3. Reported cases of extracutaneous mastocytoma

\begin{tabular}{lcccc}
\hline Investigator $($ year $)$ & Age $(\mathbf{y r})$ & Sex & Site & Therapy \\
\hline Sherwin et al. ${ }^{9}(1965)$ & 51 & Female & Lung & Resection \\
Charrette et al. $^{10}(1966)$ & 68 & Female & Lung & Resection \\
Kudo et al. $^{11}(1988)$ & 53 & Male & Lung & Resection \\
Castells $^{12}(2006)$ & 13 & Male & Skull & Resection \\
Khan et al. $^{13}(2011)$ & 30 & Female & Skull & Resection \\
Ayadi et al. $^{14}(2015)$ & 51 & Female & Lung & Resection \\
Present case $(2019)$ & 61 & Male & Colon & Resection \\
\hline
\end{tabular}

guished from mast cell sarcoma based on the histological findings. Although the two types of tumors are unifocal tumors, mast cell sarcoma exhibits an aggressively destructive (sarcoma-like) growth pattern. Mastocytoma mast cells exhibit lowgrade cytology, while mast cell sarcoma is composed of highly atypical (poorly differentiated) mast cells. ${ }^{7}$ This patient was diagnosed with mastocytosis through biopsy after endoscopic mucosal resection of the lesions found in the large intestine. Since there were no abnormal findings, he was diagnosed with extracutaneous mastocytoma without further bone marrow biopsy or molecular examination following the NCCN guidelines.

The newly diagnosed large intestine's extracutaneous mastocytoma and the frequently detected tubular adenoma are different in terms of the following endoscopic findings. On endoscopy, a tubular adenoma is characterized by a predominantly smooth surface in smaller tumors and a rough, lobular appearance in larger tumors. In this case, a cerebral gyrus-like surface was observed. However, the swollen lesion did not have a neck and did not exhibit a destructive pattern. It had a brighter (whitish) color than the surrounding colonic mucosa. It was also distinguished from systemic mastocytosis, which invades the entire gastrointestinal tract and presents with various endoscopic findings such as inflammation, ulcers, hyperplasia of mucous folds, polyps, and dilation of vessels (Table 2). ${ }^{8}$

Extracutaneous mastocytoma is a rare condition; previously reported cases, including those experienced by the authors, are summarized in Table $3 .^{9-14}$ Seven cases of extracutaneous mastocytoma, including those encountered by the authors, were identified. This included four cases in the lungs, two in the skull, and one in the colon. In this case, the tissue tests conducted after removing the lesions were diagnosed as mastocytosis. The subsequent basic tests had unremarkable findings and excluded systemic diseases. Thus, the patient was diagnosed and his progress was monitored. Mastocytosis can either be benign or malignant, according to its classification. When evaluating lesions in asymptomatic mastocytosis patients, basic tests, such as further history taking, physical examination, and blood testing can be performed to rule out systemic diseases. The results of these tests will dictate whether additional examinations, such as a bone marrow biopsy or molecular genetic testing, are needed.

\section{Conflicts of Interest}

The authors have no potential conflicts of interest.

\section{Funding}

None.

\section{Author Contributions}

Conceptualization: EJK; Investigation: MSC; Supervision: EJK; Writing-original draft: MSC; Writing-review \& editing: EJK. 


\section{ORCID}

Min Su Chu

Eui Joong Kim

https://orcid.org/0000-0002-1647-226X

https://orcid.org/0000-0001-5031-0259

\section{REFERENCES}

1. Valent P, Akin C, Metcalfe DD. Mastocytosis: 2016 updated WHO classification and novel emerging treatment concepts. Blood 2017; 129:1420-1427.

2. Gotlib J, Gerds AT, Bose P, et al. Systemic mastocytosis, Version 2. 2019, NCCN Clinical Practice Guidelines in Oncology. J Natl Compr Canc Netw 2018;16:1500-1537.

3. Brockow K. Epidemiology, prognosis, and risk factors in mastocytosis. Immunol Allergy Clin North Am 2014;34:283-295.

4. Matito A, Azaña JM, Torrelo A, et al. Cutaneous mastocytosis in adults and children: new classification and prognostic factors. Immunol Allergy Clin North Am 2018;38:351-363.

5. Leung AKC, Lam JM, Leong KF. Childhood solitary cutaneous mastocytoma: clinical manifestations, diagnosis, evaluation, and management. Curr Pediatr Rev 2019;15:42-46.

6. Cohen PR. Solitary mastocytoma presenting in an adult: report and literature review of adult-onset solitary cutaneous mastocytoma with recommendations for evaluation and treatment. Dermatol Pract
Concept 2016;6:31-38.

7. Valent P, Horny HP, Escribano L, et al. Diagnostic criteria and classification of mastocytosis: a consensus proposal. Leuk Res 2001; 25:603-625

8. Jensen RT. Gastrointestinal abnormalities and involvement in systemic mastocytosis. Hematol Oncol Clin North Am 2000;14:579623.

9. Sherwin RP, Kern WH, Jones JC. Solitary mast cell granuloma (histiocytoma) of the lung; a histopathologic, tissue culture and timelapse cinematographic study. Cancer 1965;18:634-641.

10. Charrette EE, Mariano AV, Laforet EG. Solitary mast cell "tumor" of lung. Its place in the spectrum of mast cell disease. Arch Intern Med 1966;118:358-362.

11. Kudo H, Morinaga S, Shimosato Y, et al. Solitary mast cell tumor of the lung. Cancer 1988;61:2089-2094.

12. Castells MC. Extracutaneous mastocytoma. J Allergy Clin Immunol 2006;117:1513-1515.

13. Khan K, Kupferman ME, Gardner JM, et al. Solitary mastocytoma in an adult with an unusual clinical presentation. J Am Acad Dermatol 2011;65:683-684

14. Ayadi L, Abid N, Makni S, et al. An unusual tumour of the lung. Pathologica 2015;107:14-18. 